Supplementary Material to the paper

\title{
Technetium Complexes with Triazacyclononane
}

\author{
Henrik Braband and Ulrich Abram*
}

Freie Universität Berlin, Institut für Chemie, Fabeckstr. 34-36, 14195 Berlin, Germany.

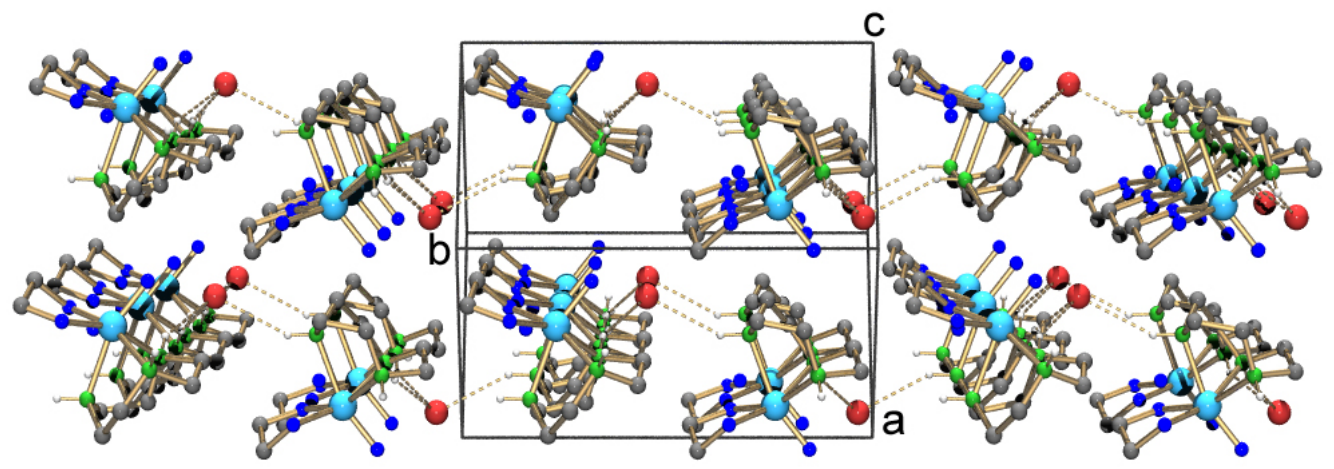

Fig. S1: Illustration of the two-dimensional network in $\left[\mathrm{TcO}\left(\mathrm{OC}_{2} \mathrm{H}_{4} \mathrm{O}\right)(\operatorname{tacn})\right] \mathrm{Br} \cdot \mathrm{H}_{2} \mathrm{O}$, formed by hydrogen bonds between the nitrogen atoms of the tacn ligands and the bromide counter ions. Water molecules are omitted for clarity.

\begin{tabular}{lcccr}
\hline D-H...A & d(D-H) & d(H...A & d(D...A $)$ & $<$ (DHA) \\
\hline N(1)-H(1)..Br(1)\#1 & 0.91 & 2.58 & $3.407(3)$ & 152.1 \\
N(2)-H(2)..Br(1)\#2 & 0.91 & 2.55 & $3.383(3)$ & 152.3 \\
N(3)-H(3)..Br(1)\#3 & 0.91 & 2.50 & $3.385(3)$ & 165.7 \\
\hline
\end{tabular}

Symmetry transformations used to generate equivalent atoms:

$\# 1-\mathrm{x}+1, \mathrm{y}+1 / 2,-\mathrm{z}+1 \quad \# 2 \mathrm{x}, \mathrm{y}, \mathrm{z}-1 \quad \# 3 \mathrm{x}+1, \mathrm{y}, \mathrm{z}$

Table S1: $\quad$. Hydrogen bonds for $\left[\mathrm{TcO}\left(\mathrm{OC}_{2} \mathrm{H}_{4} \mathrm{O}\right)(\operatorname{tacn})\right] \mathrm{Br} \cdot \mathrm{H}_{2} \mathrm{O}\left[\AA\right.$ and $\left.{ }^{\circ}\right]$. 


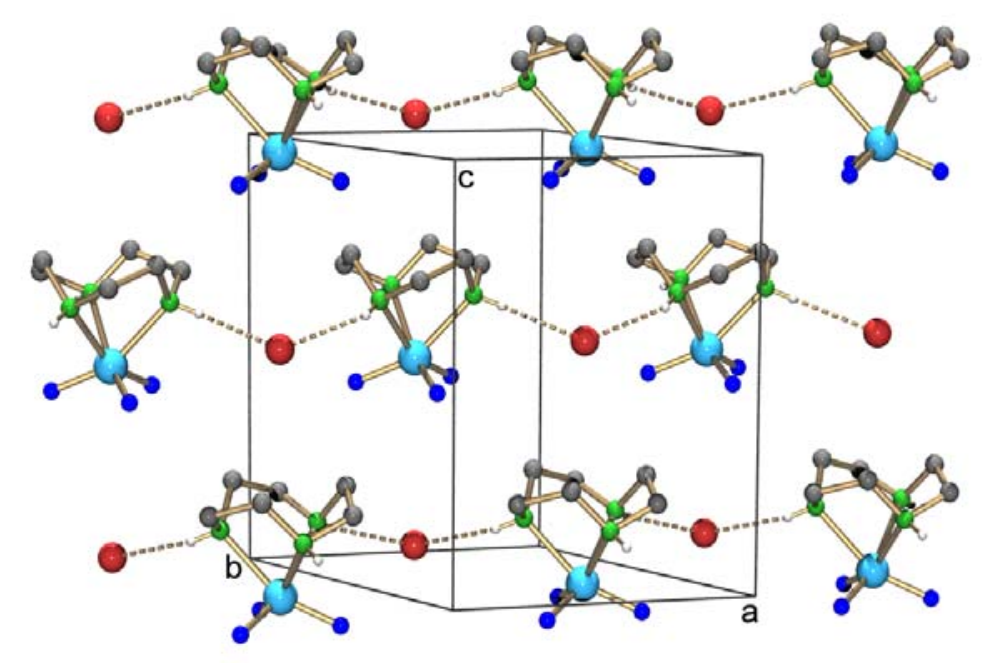

Fig. S1: Illustration of the network in $\left[\mathrm{TcO}_{3}(\operatorname{tacn})\right] \mathrm{Br}$, formed by hydrogen bonds between the nitrogen atoms of the tacn ligands and the bromide counter ions. For clarity the network is shown just in one-dimension.

\begin{tabular}{lllll}
\hline D-H...A & d(D-H) & d(H...A & $d(\mathrm{D} \ldots \mathrm{A})$ & $<$ (DHA) \\
\hline $\mathrm{N}(1)-\mathrm{H}(1) \ldots \mathrm{Br}(1)$ & $0.82(7)$ & $2.58(8)$ & $3.289(5)$ & $146(5)$
\end{tabular}

Symmetry transformations used to generate equivalent atoms:

\#1 -y+1,x-y,z \#2-x+y+1,-x+1,z

Table S2: $\quad$. Hydrogen bonds for $\left[\mathrm{TcO}_{3}(\operatorname{tacn})\right] \mathrm{Br}\left[\AA\right.$ and $\left.{ }^{\circ}\right]$. 